\title{
Factores endógenos y exógenos que impactan en el uso de la biblioteca en tres universidades del área metropolitana de Monterrey, Nuevo León
}

José Segoviano Hernández

Miguel Ángel Palomo González

José Luis Cantú Mata *

Artículo recibido:

11 de febrero de 2013.

Artículo aceptado:

2 de mayo de 2013.

\section{RESUMEN}

La presente investigación se propuso identificar los factores que motivan a los estudiantes de tres instituciones de educación superior del área metropolitana de Monterrey a utilizar la biblioteca universitaria. Para abordar la cuestión se diseñó un modelo de análisis multivariable que integra nueve factores, los cuales se desprenden de la propia operación de la biblioteca (factores endógenos), así como del contexto académico y cultural en el cual ésta efectúa su función (factores exógenos). El modelo se aplicó a las percepciones de una muestra estratificada de alumnos de sexto semestre de las tres instituciones participantes, medidas

* Los tres autores pertenecen a la Universidad Autónoma de Nuevo León, México. (José S.: jose_segoviano01@hotmail.com); (Miguel: mpalomo2012@yahoo. com); (José L.: jlcmata@gmail.com)

INVESTIGACIÓN BIBLIOTECOLÓGICA, Vol. 27, Núm.61, septiembre/diciembre, 2013, México, ISSN: 0187-358X. pp. 53-81 
con el auxilio de una escala de Likert. Los resultados comprobaron la predicción del modelo y mostraron la existencia de cinco variables que impactan de manera significativa en el uso de la biblioteca universitaria. Posteriormente se analizaron muestras individuales de las tres instituciones y se agrupó a los alumnos en tres áreas de conocimiento. Se obtuvieron resultados significativos diferentes en cada una de las muestras.

Palabras clave: Bibliotecas universitarias; Estudios de usuarios; Uso de la biblioteca; Análisis multivariable; Uso de la información.

\section{Abstract}

Exogenous and endogenous factors that impact on the use of the library at three universities in metropolitan Monterrey, Nuevo Leon

José Segoviano-Hernández, Miguel Ángel Palomo-González and José Luis Cantú-Mata

The purpose of this research was to identify the factors that motivate students to use libraries in three universities in metropolitan Monterrey. The study employed a multivariate analysis model incorporating factors associated exclusively with the library's operation (endogenous factors) and factors associated with the academic and cultural context in which the library operates (exogenous factors). A stratified sample of sixth semester students enrolled in the three universities responded to the instrument designed to measure the target perceptions. Results show that five variables (out of nine) predicted by the model in fact significantly influence use of the university library. Additionally, the study analyzes individual samples from the three universities, grouping these into three major knowledge areas. Measures of library use for these groups are significantly distinct.

Keywords: University libraries; Users studies; Use of the library; Multivariate analysis; Use of information. 


\section{Planteamiento del problema}

T a biblioteca, su función conservadora de documentos, las necesidades de Linformación de sus usuarios y el acceso a la información y al conocimiento son temas que conciernen a la bibliotecología y la documentación (Delgado, 2002); a este respecto, si la realidad estuviera gobernada por la lógica, en palabras de González "la línea de investigación más desarrollada en el contexto de la bibliotecología y la documentación, sería la del estudio de las necesidades de información de los usuarios, habida cuenta de que los sistemas y servicios de información existen en virtud de su satisfacción" (2005: 17).

Sin embargo, el panorama al que nos enfrentamos a comienzos del siglo XXI no refleja esa realidad, ya que

[...] hasta hace unos pocos años (y nos atrevemos a decir que incluso hoy en día en buena cantidad de centros) el único análisis que se hacía de la actuación de una biblioteca o de un centro de documentación era puramente cuantitativo y referido a unos cuantos ítems predeterminados e invariables (número de ejemplares comprados, número de préstamos realizados y subdivisión de esos préstamos por sexo, edad o temas; número de revistas vaciadas; número de fotocopias solicitadas, etc.) (Fuentes, 1999: 29).

En este mismo sentido, González considera que "pese a la existencia de literatura publicada sobre el tema, las bases metodológicas y el marco de referencia para el estudio de necesidades de información aún no están resueltas ni su forma de abordaje consensuada" (2005: 17).

En concordancia con lo anterior, tras efectuar un repaso de las investigaciones que sobre necesidades de información se han realizado en el mundo -incluidos México y los países de América Latina-, Calva observa que en el fenómeno de las necesidades de información (que él divide en tres fases, a las que denomina Modelo NEIN: surgimiento de la necesidad, comportamiento informativo y satisfacción de la necesidad)

[...] la fase que atrae un mayor número de investigaciones es la correspondiente al comportamiento informativo. Esto deja de lado las investigaciones que se refieren al surgimiento de las necesidades de información y la identificación de éstas, y por supuesto son casi inexistentes las referidas a la satisfacción de dichas necesidades informativas (2004: 51, las cursivas son nuestras).

Como puede observarse a partir del análisis de Calva, el surgimiento de las necesidades de información es un tópico aún pendiente de investigar a 
fondo, toda vez que las investigaciones suelen centrarse en los usuarios cuando la necesidad de información ya se ha hecho presente en éstos y se encuentra en proceso de ser satisfecha. ${ }^{1}$

Estas lagunas en la investigación bibliotecológica han sido también claramente señaladas en el ámbito específico de las bibliotecas universitarias, pues como observan Simmonds y Andaleeb (2001), aunque se ha escrito acerca de temas tales como la accesibilidad, los acervos y los servicios de las bibliotecas universitarias, es muy poco significativo lo que se ha escrito sobre los factores que influyen realmente para que los alumnos utilicen esas bibliotecas. Coinciden con este planteamiento Calvert (2001), al señalar que un problema relacionado con el uso de la biblioteca universitaria es nuestra parcial comprensión de las expectativas de sus consumidores, y el estudio de Oakleaf (2010) para la Association of College and Research Libraries, en el cual se afirma la necesidad de realizar investigación basada en evidencia sobre el impacto y el valor de la biblioteca universitaria.

Las anteriores aseveraciones sobre la utilidad de las bibliotecas, particularmente las universitarias, para satisfacer las necesidades de información de sus usuarios serían de interés puramente metodológico si no fuera por dos condiciones registradas en la literatura bibliotecológica de los últimos años:

a) Por una parte, parece existir un descenso continuo en el nivel de uso de las bibliotecas universitarias en diversas partes del mundo. Así lo sugieren, para el caso de los Estados Unidos, los estudios de Jones y Madden (2002) y el de Martell (2008), y para el caso del Reino Unido, el estudio de Toner (2008). Estos autores observan la aparición de una masa cada vez mayor de no usuarios en el ámbito de las bibliotecas académicas; una masa que es observable en términos estadísticos, pero cuyas motivaciones aún no se han esclarecido plenamente. Al respecto, Louise Flowers, de la Upper Goulburn, en Australia, percibe que hasta el momento el profesional no reconoce plenamente el tema de los no usuarios, probablemente porque sólo hay un pequeño cuerpo de investigaciones que abordan este problema (Flowers, citada por Toner, 2008).

b) Por otra parte, parece existir una relación demostrable entre la frecuencia de uso de la biblioteca universitaria y la presencia de diversos factores que condicionan las percepciones y conductas de los usuarios. Esto significa que el éxito de la biblioteca universitaria en el

1 En cuanto a la otra carencia notada por Calva, la de investigaciones en torno a la satisfacción de las necesidades de información, nos ha parecido importante hacerla notar en este texto, pero se encuentra fuera de los alcances del presente estudio. 
cumplimiento de sus fines se halla en función del conocimiento que los bibliotecarios tengan acerca de las expectativas, preferencias, hábitos y destrezas de sus usuarios. Así parecen demostrarlo el estudio de Lee (2007) sobre las motivaciones de los usuarios de bibliotecas universitarias y el de Lovato-Gassman (2007) enfocado en la satisfacción del usuario. Así lo señala también, de manera indirecta, Mason (2010) cuando advierte que la mayoría de los alumnos que inician la universidad no tienen experiencia en bibliotecas grandes ni han adquirido las habilidades necesarias para investigar en ellas; lo que está sugiriendo con esto es que, si las bibliotecas universitarias no prestan atención a la capacidad efectiva de sus usuarios para satisfacer sus necesidades de información, entonces las probabilidades de éxito de las propias bibliotecas se reducirán de manera significativa.

Es en este horizonte abierto aún plenamente a la investigación y a la búsqueda de generalizaciones en el que deseamos situar el presente estudio, el cual versa sobre las motivaciones que existen para usar las bibliotecas universitarias en el área metropolitana de Monterrey, Nuevo León.

Este estudio busca identificar los factores que motivan a los estudiantes de tres instituciones de educación superior de la mencionada área metropolitana a utilizar la biblioteca universitaria. Para abordar esta cuestión hemos creado un modelo de análisis multivariable que integra en una misma investigación factores endógenos y exógenos; es decir, factores que se desprenden de la propia operación de la biblioteca (endógenos) y factores que se desprenden del contexto académico y cultural en el cual la biblioteca efectúa su función (exógenos).

\section{IDENTIFICACIÓN DE LOS FACTORES ENDÓGENOS Y EXÓGENOS}

Para los propósitos de la presente investigación, y con la finalidad explícita de establecer una tipología que permita en el futuro comprender de manera diferenciada los diversos factores que influyen en la motivación para el uso de la biblioteca, establecemos las siguientes definiciones:

a) Factores endógenos: son factores motivadores del uso de la biblioteca que, haciéndose presentes en la percepción del usuario potencial cuando surge en éste una necesidad de información, constituyen parte de las operaciones habituales de la biblioteca y se encuentran por lo tanto en la posibilidad de ser controlados por ésta. 
b) Factores exógenos: son factores motivadores del uso de la biblioteca que, haciéndose presentes en la percepción del usuario potencial cuando surge en éste una necesidad de información, forman parte del contexto cultural y académico en el cual la biblioteca efectúa sus funciones, pero son ajenos a las operaciones de la misma. ${ }^{2}$

Para la definición de ambos tipos de factores nos hemos basado en experiencias de estudios de usuarios registradas por la literatura bibliotecológica, de manera que nuestro estudio constituya un aporte a líneas más amplias de investigación.

En relación con los factores endógenos, suscribimos la observación de Booth (2008), quien afirma que una biblioteca es por lo menos, y en la mayoría de los casos, un lugar físico, con colecciones organizadas y un virtual proveedor de servicios. La afirmación de Booth lleva implícitas las tres dimensiones de la encuesta LibQual+, una encuesta desarrollada por la Association of Research Libraries (ARL) que ha sido ampliamente difundida y es de hecho un estándar de evaluación de la calidad de las bibliotecas universitarias (Red de Bibliotecas Universitarias, 2007). De las tres dimensiones consideradas por LibQual+ (valor afectivo del servicio, la biblioteca como lugar y control de la información) hemos desprendido los factores endógenos que vamos a examinar en nuestro estudio: competencia del bibliotecario, espacio físico disponible e información disponible en la biblioteca.

En relación con los factores exógenos, la literatura bibliotecológica recoge variadas referencias a factores que de manera observable y recurrente impactan de manera positiva o negativa la frecuencia y modos de uso de las bibliotecas universitarias. Así por ejemplo, Whitmire (2001) observa que los hábitos de estudio adquiridos por los estudiantes en el bachillerato impactan en la frecuencia con la cual los mismos estudiantes utilizarán la biblioteca de su universidad. Otros factores que impactan significativamente el uso de la biblioteca universitaria observados por esta autora son la interacción de alumnos y profesores y la realización de actividades académicas que implican la realización de trabajos escritos.

Los hallazgos de Whitmire, efectuados en los Estados Unidos, se confirman en la investigación que Arias y Simón desarrollaron sobre el caso de la Universidad Complutense de Madrid. También en ese caso la influencia de los

2 Dejamos por ahora de lado la cuestión de en qué medida la biblioteca puede controlar los factores exógenos que la afectan. Sin duda, en virtud de los lazos que la biblioteca y los bibliotecarios establecen con su entorno, la biblioteca puede al menos minimizar la influencia de algunos factores que le resultan negativos, así como propiciar o potenciar los factores que tienen sobre ella un efecto benéfico. Pero por ahora sólo queremos subrayar que se trata de factores que no se originan en la biblioteca, sino en y para el entorno en que ésta se desenvuelve. 
profesores y la realización de algún tipo especial de actividades académicas basadas en la escritura y la investigación son factores que impactan positivamente en la frecuencia con que los alumnos usan la biblioteca:

La relación entre actividades que se realizan con mayor frecuencia y el grado de asistencia a las clases teóricas, sugiere la importancia que tiene la metodología docente en la dirección de las actividades realizadas por el estudiante: realizar trabajos pedidos por el profesor, o búsqueda de la bibliografía recomendada (2008: 428).

Pero quizás el factor exógeno de mayor relevancia, según estos autores, sea la transformación del modelo educativo, que obligaría a replantear incluso la misión de la biblioteca al servicio de la educación superior:

Esta visión de la biblioteca como lugar de trabajo individual y colectivo puede verse reforzada con la adaptación de la universidad al Espacio Europeo de Educación Superior, donde se prevé una modificación profunda del actual modelo educativo basado en un predominio de la enseñanza presencial en el aula, con una sobrecarga de horas lectivas para el estudiante que le imposibilita el disponer de tiempo suficiente para el estudio y la reflexión. La nueva filosofía nos orienta hacia otro modelo centrado en el aprendizaje activo de los estudiantes en el que deben adquirir nuevas competencias tales como las de trabajo en grupo, la capacidad de resolver problemas, el uso de las tecnologías de la comunicación e información, o "aprender a aprender" para hacer posible el objetivo de aprendizaje a lo largo de la vida.

Este nuevo paradigma docente obliga a revisar la misión de la biblioteca universitaria, al menos en lo que hace referencia a los estudiantes, y a planificar una mayor integración en el proceso de enseñanza y aprendizaje mediante la potenciación de la biblioteca como lugar de trabajo de los estudiantes y de socialización de la información y el conocimiento, con el diseño de nuevos espacios para el trabajo individual y en grupo, con la participación en la implantación y difusión de las tecnologías de la información y comunicación dentro de sus instalaciones y en las aulas y laboratorios, y la participación en la formación de los estudiantes en el uso de estas tecnologías (2008: 428).

Otro posible factor, la conciencia que los usuarios tienen del valor de la información, se perfila en la investigación de Teoh y Tan (2011). En este caso los antecedentes familiares parecen haber sembrado en el alumno esa conciencia. Estos autores observan que si los padres son conscientes del valor de la biblioteca, es más probable que inculquen en sus hijos esta conciencia, por ejemplo llevándolos a la biblioteca desde que son niños, de manera que 
cuando los hijos crecen se convierten en usuarios efectivos de su biblioteca universitaria.

Otro factor de posible impacto en el uso de la biblioteca universitaria es la posesión y desarrollo, por parte de los usuarios, de las llamadas babilidades informativas. Éstas son las características o competencias que deben desarrollar las personas para que puedan ser llamadas "alfabetas en el uso de la información”, como lo describe la American Library Asociation (ALA), citada por Lau y Cortés:

Esencialmente, las personas alfabetas en el uso de la información son aquellas que han aprendido cómo aprender. Saben cómo aprender porque saben cómo está organizado el conocimiento, cómo encontrar la información y como usar la información de manera que otros puedan aprender de ellos. Son gente preparada para el aprendizaje de toda la vida, porque pueden encontrar siempre la información requerida para cualquier tarea o decisión que tengan enfrente [independientemente del soporte en que se encuentre, esto es: impreso, digital, en línea, etc.] (2005: 6).

De lo anterior se infiere que las bibliotecas deben realizar una labor intensa de información y motivación, y que esta labor podría impactar de alguna manera en la frecuencia y modo de uso de la biblioteca, pues el usuario alfabeta en el uso de la información tendría que reconocer el valor de la entidad que esencialmente se dedica a acopiar y organizar la información. Así parece haber ocurrido en la Universidad Autónoma de Ciudad Juárez, que logró incorporar al currículo un programa de desarrollo de habilidades informativas, a través de una materia que se denominó Desarrollo de Competencias Informativas. En las conclusiones de Cortés (2007), los estudiantes que han cursado esta materia expresan su reconocimiento a lo interesante e importante de los temas abordados, así como a la utilidad que las competencias desarrolladas les brindarán durante su paso por la universidad e incluso más adelante, durante su vida personal.

Entre los factores exógenos hay que tomar en cuenta también el factor tecnológico, pues como observaron por ejemplo Lau y Cortés (1995), los usuarios que no disponen de un bagaje de habilidades en el manejo de la información obtendrán resultados menos satisfactorios al utilizar dispositivos y soportes de información no tradicionales. Refiriéndose de manera específica al impacto que dicho factor tiene en el uso de la biblioteca, los ya citados Arias y Simón (2008) observaron, a partir de una revisión de la literatura, que la preferencia de los alumnos universitarios por el uso de Internet y de los recursos electrónicos podría impactar de forma negativa el grado de uso de la biblioteca universitaria. Martell (2008) y Toner (2008) coinciden con ello al señalar que las 
visitas físicas a la biblioteca universitaria se ven impactadas de manera negativa en virtud de que los usuarios pueden completar las tareas de sus cursos e investigaciones sin visitar físicamente la biblioteca.

Pero lo anterior no significa que la biblioteca tradicional y las tecnologías de la información deban enfrentarse entre sí. Por el contrario, cabe hablar de intentos exitosos de integración entre bibliotecas y tecnologías, en donde las bibliotecas podrían contribuir a que el usuario haga un uso más eficaz de las tecnologías. Como observa Palma, las bibliotecas "se consolidarán como intermediarias esenciales para transformar los entornos educativos actuales y asegurar un aprendizaje significativo por medio de las TIC y, así, garantizarán el incremento en el nivel educativo de la sociedad" (2009: 167). De lo dicho anteriormente podemos inferir que el factor tecnológico podría tener un impacto negativo en el grado de uso de la biblioteca, al ofrecerle al usuario potencial alternativas para la utilización de la misma; pero también podría tener un impacto positivo, cuando la biblioteca lo asimila a sus servicios y se convierte en una promotora del uso de las tecnologías de la información y la comunicación. ${ }^{3}$ Así lo advierte López (2004) a propósito de las bibliotecas tradicionales y digitales. Aunque unas y otras son esencialmente distintas (las primeras son un conjunto organizado de documentos, las segundas un conjunto organizado de información), en la práctica no son mutuamente excluyentes, sino complementarias. Incluso cabe hablar de la existencia de bibliotecas hibridas, que no son otra cosa que bibliotecas que disponen de colecciones tradicionales y de servicio de biblioteca digital, tendencia también adoptada por las bibliotecas universitarias (López, 2004). En última instancia, como señala Martell (2008), la Internet puede ser una aliada para las bibliotecas universitarias, pues gracias a ésta es posible poner a disposición de los usuarios millones de recursos aprovechables a distancia.

Consideramos que los hábitos de lectura son otro posible factor exógeno. Gutiérrez (2009) nos muestra una idea clara del nivel de lectura en nuestro país. Para ello, refiere al Consejo Nacional para la Cultura y las Artes, el cual dio a conocer un estudio realizado en 2006 por la Universidad Nacional Autónoma de México: la Encuesta Nacional de Lectura. Esta encuesta permite conocer de forma particular que, si bien el sector de los estudiantes universitarios es el que más lee en promedio y más tiempo le dedica a la lectura, también es una realidad que el $18 \%$ dijo que nunca había ido a una librería, $35 \%$ reconoció que no lee literatura general, $23 \%$ que no lee libros de ningún

3 He aquí un posible ejemplo de cómo la biblioteca puede ejercer algún tipo de control sobre sus factores exógenos. Como señalamos anteriormente, no profundizaremos por ahora en esta cuestión; sólo la señalamos, a la vez que hacemos constar la necesidad de retomarla en investigaciones posteriores. 
tipo, $40 \%$ reconoció que no lee periódicos, $48 \%$ no es afecto a leer revistas, 7 \% externó no leer nada, ni libros, ni revistas ni periódicos; el $30 \%$ no gasta en libros y el $16 \%$ contestó que gasta menos de 300 pesos al año en la compra de libros. Por otra parte, si bien el $77 \%$ de los universitarios respondió que tiene su biblioteca personal, en el 68 \% de ellas hay menos de 50 libros. En virtud de estos datos, afirmamos que cabría suponer un impacto significativo y observable entre los hábitos de lectura y el uso de las bibliotecas universitarias en nuestro estudio.

Dejamos fuera de nuestro análisis algunos posibles factores exógenos que, aunque se encuentran en la literatura, no nos parecen aplicables al universo de nuestro estudio. Tal es el caso, por ejemplo, de las variables que señala Ramírez (1987) en su estudio de los factores que inciden en la frecuencia de uso de la biblioteca pública, los cuales se centran justamente en la problemática muy particular de las bibliotecas públicas, así como en las circunstancias geográficas de la ciudad de México.

\section{DEFINICIÓN DE LAS VARIABLES}

A partir de los factores endógenos o exógenos arriba señalados, hemos definido las siguientes variables para nuestro estudio:

\section{Variable dependiente}

(Y) Uso de la biblioteca

Se refiere a la percepción sobre el uso de la biblioteca física $(Y 1)$ o de la biblioteca digital (Y2) para la formación profesional. ${ }^{4}$

\section{Variables independientes endógenas y exógenas $(X)$}

\section{Variables independientes endógenas}

\section{(X1) Información disponible en biblioteca}

La conforman la percepción sobre la facilidad, rapidez, actualidad, confiabilidad y la diversidad de formatos de los materiales disponibles en la biblioteca física (X1.1) y la biblioteca digital (X1.2).

4 Para el caso, entendemos los términos "física” y "digital” de la manera más llana posible: biblioteca física es aquella que precisa ser visitada físicamente por el usuario, en tanto biblioteca digital es aquella cuyos servicios y recursos pueden aprovecharse de manera remota a través de medios digitales. 
(X2) Espacio físico disponible en biblioteca

Se conforma de la percepción sobre el espacio adecuado para estudiar con libros propios, aprender e investigar, y el ambiente para el estudio individual y el trabajo en equipo.

(X3) Competencia del bibliotecario

La conforman la percepción acerca del bibliotecario respecto a la confianza, la respuesta, la ayuda, la orientación y el trato que les brinda a los usuarios.

\section{Variables independientes exógenas}

Variables independientes exógenas académicas

\section{(X4) Programa de estudio}

Lo conforman la percepción sobre la asistencia de los alumnos a la biblioteca física y el uso de la biblioteca digital debido a las actividades de los cursos y los laboratorios, los documentos que aparecen en los programas de estudio, la intención de mejorar las calificaciones y a que la biblioteca forme parte de la evaluación de los cursos.

(X5) Influencia del profesor

La conforman la percepción sobre la asistencia de los alumnos a la biblioteca física y el uso de la biblioteca digital debido a que los profesores lo exhortan de alguna manera, por ejemplo solicitándoles directamente a los alumnos que asistan a la biblioteca o usen la biblioteca digital, no proporcionando ellos mismos los libros y demás documentos para la clase, e incitando a los alumnos a encontrar por ellos mismos la información que requieren para sus investigaciones y cursos.

(X6) Habilidades informativas

Las conforman la percepción sobre la competencia de los alumnos para identificar palabras o conceptos clave, identificar la información necesaria para fines determinados, elaborar citas y bibliografía, describir con sus propias palabras el conocimiento adquirido e identificar sinónimos cuando no encuentran un concepto.

Variables independientes exógenas culturales

(X7) Uso de Internet para actividades académicas

Se conforma de la percepción sobre el uso que los alumnos hacen de Internet debido a que es parte de las actividades de sus cursos, es una solicitud de sus profesores, encuentran mejor información para 
sus tareas o es información más accesible que la que encuentran en la biblioteca física y o en la biblioteca digital.

(X8) Hábitos de lectura

Se conforman de la percepción sobre la asistencia de los alumnos a la biblioteca física o el uso de la biblioteca digital debido al gusto personal por la lectura, al placer por frecuentar la biblioteca física o digital y a la disponibilidad de tiempo para realizar estas actividades.

(X9) Conciencia del valor de la información

Se conforma de la percepción sobre la competencia de los alumnos para documentar de forma suficiente y eficaz sus trabajos escolares, por ejemplo mostrando voluntad para profundizar en el conocimiento de los autores consultados y para anexar a sus trabajos una bibliografía adecuada en cuanto a la cantidad y calidad de las fuentes leídas.

\section{Hipótesis y MODELO GRÁFICO}

En correspondencia con la declaración del problema que origina este estudio, el cual busca identificar los factores que motivan a los estudiantes a utilizar la biblioteca universitaria en las instituciones de educación superior del área metropolitana de Monterrey, Nuevo León, se formulan, para tal fin, la hipótesis de esta investigación, la relación causa-efecto derivada de dicha hipótesis y el modelo gráfico del estudio.

\section{Hipótesis de investigación}

Los factores que motivan a los estudiantes de las instituciones de educación superior del área metropolitana de Monterrey a utilizar la biblioteca universitaria son factores endógenos y exógenos (académicos y culturales).

\section{Relación causa y efecto}

a) A mayor presencia de las variables independientes: endógenas (X1. Información disponible en biblioteca, X2. Espacio físico disponible en biblioteca y X3. Competencia del bibliotecario), habrá mayor motivación para el uso de la biblioteca en las instituciones de educación superior del área metropolitana de Monterrey.

b) A mayor presencia de las variables independientes: exógenas académicas: X4. Programa de estudio, X5. Influencia del profesor, X6. 
Habilidades informativas, y exógenas culturales: X7. Uso de Internet para actividades académicas, $X 8$. Hábitos de lectura y X9. Conciencia del valor de la información, habrá mayor motivación para el uso de la biblioteca en las instituciones de educación superior del área metropolitana de Monterrey.

\section{Modelo gráfico}

La Figura 1 contiene las relaciones hipotéticas de las variables causa-efecto consideradas para establecer el modelo teórico, mismo que se pretende confrontar con los resultados empíricos del estudio de campo.

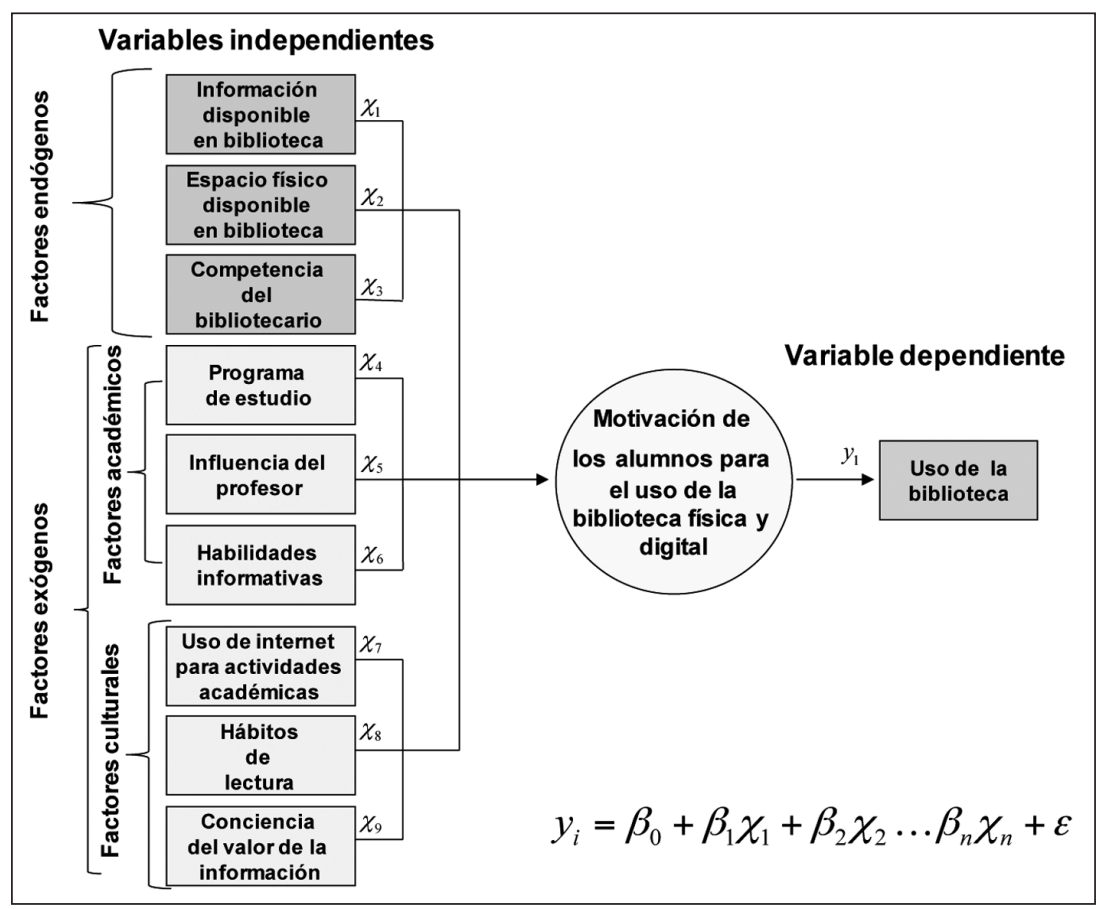

Figura 1. Modelo gráfico del estudio. Nota: Elaboración propia

\section{MÉTodo}

Para la comprobación de la hipótesis se implementó un estudio cuantitativo de corte transversal. El diseño de la investigación fue no experimental, dado que no se manipularon las variables, sino que se cuestionó a los estudiantes 
respecto a sus percepciones sobre el uso que ellos hacen de la biblioteca en su contexto natural.

La investigación se realizó en tres instituciones de educación superior (IES) de Monterrey, Nuevo León, y el estudio de campo se efectuó fuera de la biblioteca. Se elaboró un cuestionario y la información se capturó en Minitab y en SPSS, herramientas mediante las cuales se aplicó el análisis de regresión lineal múltiple, utilizándose el método de pasos sucesivos. El cuestionario fue aplicado de manera aleatoria por profesores, en las aulas de estudio de las instituciones participantes, con el fin de que los encuestados fueran tanto alumnos que asisten regularmente a la biblioteca como alumnos que no la utilizan.

\section{Delimitaciones del estudio}

Las tres instituciones participantes fueron seleccionadas porque tenían en común una biblioteca híbrida con más de cinco años de servicio. Una de las IES es universidad pública y las dos restantes son privadas; sus nombres se tratan en forma confidencial por acuerdo previo al estudio. La población objeto de estudio se limitó a los alumnos de sexto semestre de nivel profesional, por razones económicas. Se eligió el sexto semestre con el fin de captar las percepciones de los alumnos que se encuentran a mitad de sus estudios profesionales, considerando que los alumnos de los últimos semestres tienen mayor experiencia en el uso de la biblioteca y no son representativos de los alumnos de reciente ingreso, los cuales, como señala Mason (2010), en su mayoría no están preparados para manejar las demandas de sus cursos, principalmente porque no tienen experiencia en bibliotecas grandes, no saben cómo éstas trabajan y no han adquirido las habilidades necesarias para investigar en ellas. El estudio de campo se realizó durante los meses de abril y mayo de 2011 en las IES privadas y en agosto del mismo año en la IES pública.

\section{Población y muestra}

La población objeto de estudio fue de 11276 alumnos de sexto semestre que pertenecían a un universo de 96941 alumnos inscritos en las tres IES. El género de la población fue representado por $50.3 \%$ hombres y $49.7 \%$ de mujeres.

El tamaño óptimo de la muestra se acordó en 330 cuestionarios. Debido a las diferencias significativas en la cantidad de los alumnos de las tres IES, se utilizó una muestra estratificada. Dicha población se dividió en tres áreas del conocimiento: 1. Ciencias de la salud, 2. Ciencias sociales y humanidades y 3. 
el estudio de campo se distribuyeron 850 cuestionarios. De los 850 cuestionarios distribuidos se recuperaron 620, de los cuales sólo 585 resultaron completos. De estos últimos se seleccionaron 497, mediante el programa Minitab, para obtener el mejor ajuste del modelo.

\section{Características del cuestionario}

El cuestionario aplicado constó de 52 ítems que surgieron de nueve reactivos de carácter demográfico y las 10 variables del estudio que se midieron a través de una escala de Likert de cinco elementos, con los siguientes valores:

$1=$ Estoy en total desacuerdo con esta aseveración (TD).

$2=$ Estoy en desacuerdo con esta aseveración (D).

$3=$ No estoy ni de acuerdo ni en desacuerdo con esta aseveración (N).

$4=$ Estoy de acuerdo con esta aseveración (A).

$5=$ Estoy totalmente de acuerdo con esta aseveración (TA).

A los entrevistados se les solicitó su opinión sobre el uso que hacen de la biblioteca, como se muestra en la Tabla 1 . Los resultados de la prueba de confiabilidad del Alfa de Cronbach fueron: Uso de la biblioteca $(\alpha=.727), X 1$ Información disponible en biblioteca $(\alpha=.864)$, X2 Espacio físico disponible en biblioteca $(\alpha=.848)$, X3 Competencia del bibliotecario $(\alpha=.891)$, X4 Programa de estudio $(\alpha=.667)$, X5 Influencia del profesor $(\alpha=.593)$, X6 Habilidades informativas $(\alpha=.697), X 7$ Uso de Internet para actividades académicas $(\alpha=.752), X 8$ Hábitos de lectura $(\alpha=.759)$, X9 Conciencia del valor de la información $(\alpha=.829)$.

Tabla 1. Variables y preguntas del cuestionario

\begin{tabular}{|l|c|l|}
\hline Nombre de la variable & Código & \multicolumn{1}{|c|}{ Ítem (preguntas del cuestionario) } \\
\hline \multirow{3}{*}{ Uso de la biblioteca $(Y)$} & US1 & Asistir a la biblioteca es de suma importancia en mi formación profesional. \\
\cline { 2 - 3 } & US2 & $\begin{array}{l}\text { El uso de la biblioteca digital es de suma importancia en mi formación } \\
\text { profesional. }\end{array}$ \\
\hline $\begin{array}{l}\text { Información disponible } \\
\text { en biblioteca física (X1.1) }\end{array}$ & BF1 & $\begin{array}{l}\text { Es fácil encontrar información en las colecciones impresas de la } \\
\text { biblioteca. }\end{array}$ \\
\cline { 2 - 4 } & BF2 & $\begin{array}{l}\text { Es rápido encontrar información en las colecciones impresas de la } \\
\text { biblioteca. }\end{array}$ \\
\cline { 2 - 4 } & BF3 & $\begin{array}{l}\text { Utilizo los materiales impresos de la biblioteca porque contienen infor- } \\
\text { mación confiable. }\end{array}$ \\
\cline { 2 - 3 } & BF4 & $\begin{array}{l}\text { Utilizo los materiales impresos de la biblioteca porque contienen infor- } \\
\text { mación de actualidad. }\end{array}$ \\
\cline { 2 - 3 } & BF5 & $\begin{array}{l}\text { Asisto a la biblioteca porque encuentro información en diversos formatos } \\
\text { (libros y revistas, videos, mapas, microfilms, etc.) para elaborar mis tareas. }\end{array}$ \\
\hline
\end{tabular}




\begin{tabular}{|c|c|c|c|}
\hline \multirow{5}{*}{\multicolumn{2}{|c|}{$\begin{array}{l}\text { Información disponible } \\
\text { en biblioteca digital (X1.2) }\end{array}$}} & BD1 & $\begin{array}{l}\text { Uso la biblioteca digital de mi universidad porque encuentro con facilidad } \\
\text { información. }\end{array}$ \\
\hline & & $\mathrm{BD} 2$ & $\begin{array}{l}\text { Uso la biblioteca digital de mi universidad porque encuentro con rapidez } \\
\text { información. }\end{array}$ \\
\hline & & $\mathrm{BD} 3$ & $\begin{array}{l}\text { Utilizo los documentos de la biblioteca digital porque contienen informa- } \\
\text { ción actual. }\end{array}$ \\
\hline & & BD4 & $\begin{array}{l}\text { Utilizo los documentos de la biblioteca digital porque contienen informa- } \\
\text { ción confiable. }\end{array}$ \\
\hline & & BD5 & $\begin{array}{l}\text { Utilizo la biblioteca digital porque encuentro información en diversos } \\
\text { formatos. }\end{array}$ \\
\hline \multirow{5}{*}{\multicolumn{2}{|c|}{$\begin{array}{l}\text { Espacio físico disponible } \\
\text { en biblioteca }(X 2)\end{array}$}} & EF1 & $\begin{array}{l}\text { Asisto a la biblioteca porque tiene espacios adecuados para estudiar con } \\
\text { mis libros. }\end{array}$ \\
\hline & & EF2 & Asisto a la biblioteca porque tiene un ambiente adecuado para aprender. \\
\hline & & EF3 & $\begin{array}{l}\text { La biblioteca me provee de espacios adecuados cuando realizo activida- } \\
\text { des de investigación. }\end{array}$ \\
\hline & & EF4 & $\begin{array}{l}\text { Asisto a la biblioteca porque tiene espacios adecuados para el estudio } \\
\text { individual. }\end{array}$ \\
\hline & & EF5 & Asisto a la biblioteca porque tiene espacios para el trabajo en equipo. \\
\hline \multirow{5}{*}{\multicolumn{2}{|c|}{$\begin{array}{l}\text { Competencia del } \\
\text { bibliotecario }(X 3)\end{array}$}} & $\mathrm{C} 01$ & Asisto a la biblioteca por la confianza que me inspiran los bibliotecarios. \\
\hline & & $\mathrm{CO2}$ & $\begin{array}{l}\text { Busco la ayuda del bibliotecario porque responde satisfactoriamente a } \\
\text { mis preguntas. }\end{array}$ \\
\hline & & $\mathrm{CO3}$ & $\begin{array}{l}\text { Busco la ayuda del bibliotecario porque me ayuda satisfactoriamente en } \\
\text { mis búsquedas de información. }\end{array}$ \\
\hline & & $\mathrm{C04}$ & $\begin{array}{l}\text { Busco la ayuda del bibliotecario porque me orienta en el uso de la } \\
\text { biblioteca. }\end{array}$ \\
\hline & & $\mathrm{C05}$ & Busco la ayuda del bibliotecario por su trato amable. \\
\hline \multirow{5}{*}{\multicolumn{2}{|c|}{$\begin{array}{l}\text { Programa } \\
\text { de estudio }(X 4)\end{array}$}} & PE1 & $\begin{array}{l}\text { Las actividades de mis cursos, materias o laboratorios, me despiertan la } \\
\text { necesidad de asistir con frecuencia a la biblioteca. }\end{array}$ \\
\hline & & PE2 & $\begin{array}{l}\text { Uso la biblioteca digital de mi universidad porque contiene documentos } \\
\text { que aparecen en los programas de mis cursos, materias o laboratorios. }\end{array}$ \\
\hline & & PE3 & $\begin{array}{l}\text { Asisto a la biblioteca porque estoy convencido de que me ayudará a } \\
\text { mejorar mis calificaciones. }\end{array}$ \\
\hline & & PE4 & Asisto a la biblioteca a estudiar para los exámenes. \\
\hline & & PE5 & $\begin{array}{l}\text { Asisto a la biblioteca porque asistir a ella forma parte de la evaluación } \\
\text { del curso. }\end{array}$ \\
\hline \multirow{5}{*}{\multicolumn{2}{|c|}{$\begin{array}{l}\text { Influencia } \\
\text { del profesor (X5) }\end{array}$}} & IP1 & Asisto a la biblioteca porque mis profesores me lo solicitan. \\
\hline & & IP2 & Suelo estudiar en la biblioteca con los apuntes de mis profesores. \\
\hline & & IP3 & $\begin{array}{l}\text { Mis profesores me hacen ir a la biblioteca porque no me facilitan ellos los } \\
\text { libros o copias de documentos que utilizamos en clase. }\end{array}$ \\
\hline & & IP4 & $\begin{array}{l}\text { Mis profesores prefieren que utilice información de la biblioteca digital de } \\
\text { mi universidad. }\end{array}$ \\
\hline & & IP5 & $\begin{array}{l}\text { Asisto a la biblioteca porque a veces es la única manera que tengo de } \\
\text { encontrar la información que los profesores me solicitan. }\end{array}$ \\
\hline \multirow{2}{*}{\multicolumn{2}{|c|}{$\begin{array}{l}\text { Habilidades } \\
\text { informativas }(x 6)\end{array}$}} & HI1 & $\begin{array}{l}\text { Cuando me dispongo a buscar información, tengo claros los conceptos } \\
\text { clave que voy a necesitar para localizarla. }\end{array}$ \\
\hline & & $\mathrm{HI} 2$ & $\begin{array}{l}\text { Es sencillo identificar si la información que necesito se encuentra en un } \\
\text { libro, video, revista, página web, etcétera. }\end{array}$ \\
\hline
\end{tabular}




\begin{tabular}{|c|c|c|}
\hline & HI3 & $\begin{array}{l}\text { Cuando investigo, elaboro la cita o ficha bibliográfica de los libros y } \\
\text { revistas. }\end{array}$ \\
\hline & $\mathrm{HI} 4$ & $\begin{array}{l}\text { Al realizar una lectura, puedo describir con mis propias palabras el } \\
\text { conocimiento adquirido. }\end{array}$ \\
\hline & HI5 & $\begin{array}{l}\text { Cuando no encuentro un concepto que estoy buscando, identifico sus } \\
\text { sinónimos. }\end{array}$ \\
\hline \multirow{5}{*}{$\begin{array}{l}\text { Uso de Internet } \\
\text { para actividades } \\
\text { académicas }(X 7)\end{array}$} & $\mid A 1$ & $\begin{array}{l}\text { Las actividades de mis cursos, materias o laboratorios me hacen utilizar } \\
\text { información de Internet. }\end{array}$ \\
\hline & IA2 & $\begin{array}{l}\text { Mis profesores prefieren que consulte información en Internet para sus } \\
\text { materias. }\end{array}$ \\
\hline & IA3 & En Internet encuentro la mejor información para elaborar mis tareas. \\
\hline & IA4 & $\begin{array}{l}\text { La información de Internet es más accesible que la que encuentro en la } \\
\text { biblioteca. }\end{array}$ \\
\hline & IA5 & $\begin{array}{l}\text { La información de Internet es más accesible que la que encuentro en la } \\
\text { biblioteca digital. }\end{array}$ \\
\hline \multirow[t]{5}{*}{ Hábitos de lectura $(X 8)$} & HL1 & Mi gusto personal por la lectura me lleva a asistir a la biblioteca. \\
\hline & HL2 & $\begin{array}{l}\text { Al año, por placer, leo al menos un libro de la biblioteca que no es parte } \\
\text { de la carga académica. }\end{array}$ \\
\hline & HL3 & $\begin{array}{l}\text { Al año, por placer, leo al menos un libro que compro en las librerías y que } \\
\text { no es parte de la carga académica. }\end{array}$ \\
\hline & HL4 & $\begin{array}{l}\text { Leo por placer artículos de la biblioteca digital que no son parte de la } \\
\text { carga académica. }\end{array}$ \\
\hline & HL5 & $\begin{array}{l}\text { Por el momento, la carga académica no me permite leer libros de mi } \\
\text { interés personal. }\end{array}$ \\
\hline \multirow[t]{5}{*}{$\begin{array}{l}\text { Conciencia del valor de } \\
\text { la información }(x 9)\end{array}$} & VI1 & $\begin{array}{l}\text { Cuando copio un documento para una tarea procuro siempre mencionar } \\
\text { a su autor. }\end{array}$ \\
\hline & $\mathrm{VI} 2$ & Cuando elaboro tareas escolares, cito a los autores consultados. \\
\hline & $\mathrm{VI3}$ & Cuando elaboro tareas escolares, utilizo autores reconocidos. \\
\hline & VI4 & $\begin{array}{l}\text { Cuando elaboro tareas escolares, incluyo la bibliografía de los libros que } \\
\text { consulté. }\end{array}$ \\
\hline & VI5 & $\begin{array}{l}\text { Cuando elaboro tareas escolares, busco documentos en la biblioteca o } \\
\text { en la biblioteca digital y posteriormente descarto los de menor calidad. }\end{array}$ \\
\hline
\end{tabular}

\section{Resultados}

En el análisis descriptivo se obtuvo que el género de los participantes fue de $49.9 \%$ hombres y $50.1 \%$ mujeres.

La periodicidad con que declararon asistir a la biblioteca física fue: (1) Una vez al semestre o menos, $4.69 \%$; (2) Una vez al mes, $11.5 \%$; (3) Una vez a la quincena, $16.4 \%$; (4) Una vez a la semana, $31.6 \%$; y (5) Todos o casi todos los días, $35.9 \%$. Respecto a las declaraciones sobre la periodicidad con que utilizan la biblioteca digital de su universidad, se encontró lo siguiente: (1) Una vez al semestre o menos, $40.3 \%$; (2) Una vez al mes, $16.8 \%$; (3) Una vez a la quincena, $12.3 \%$; (4) Una vez a la semana, $20.3 \%$; y (5) Todos 
o casi todos los días, $10.3 \%$. Como se puede apreciar en las Figuras 2 y 3, la biblioteca digital es menos utilizada respecto a la biblioteca física. Se observa también en la biblioteca física que el uso aumenta con la periodicidad; sin embargo, la biblioteca digital presenta lo contrario.

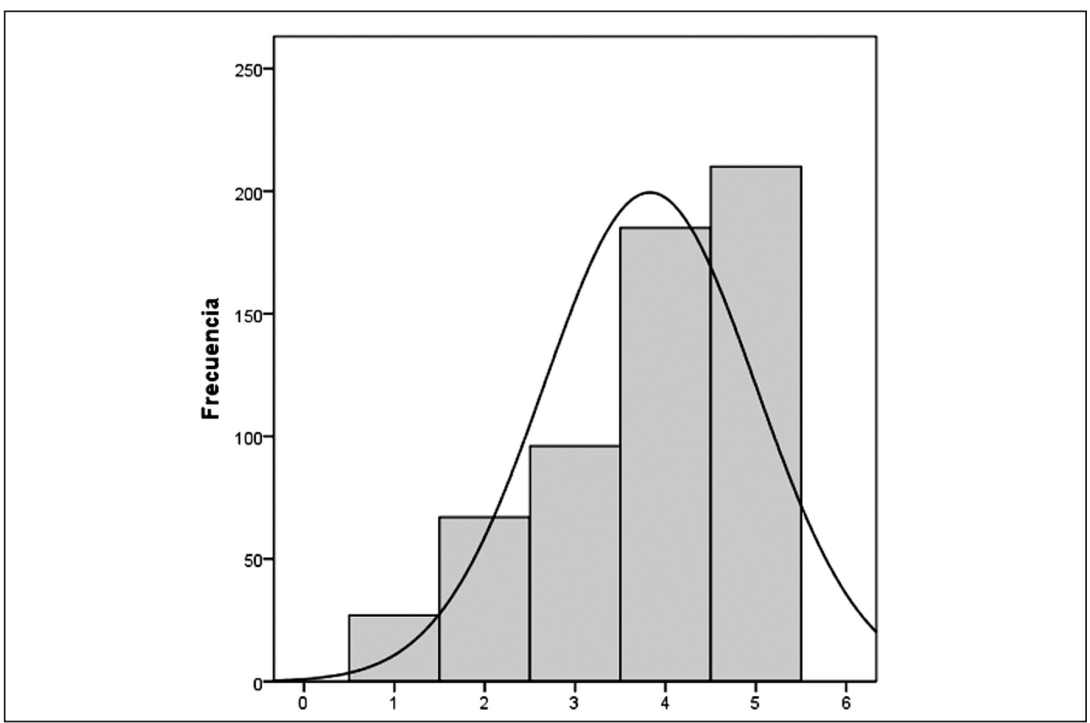

Figura 2. Histograma Asisto a biblioteca física

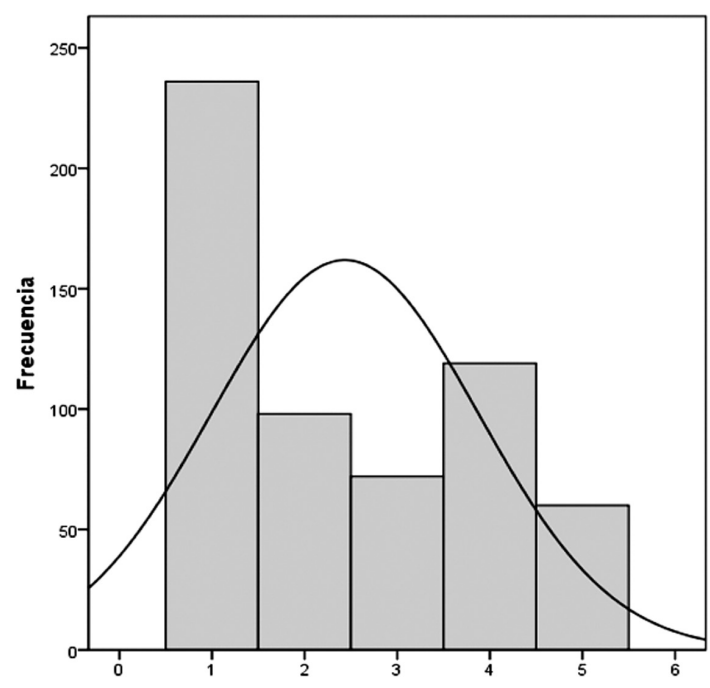

Figura 3. Histograma Asisto a biblioteca digital 
En cuanto a los resultados respecto a las afirmaciones sobre la biblioteca, se obtuvo: (1) Siempre tiene la información que necesito, 18.3 \%; (2) Generalmente tiene la información que necesito, pero debo buscar también información en Internet, 59.1 \%; (3) Generalmente no tiene la información que necesito y debo buscarla en Internet, $9.6 \%$; (4) La biblioteca es complementaria, Internet es ahora mejor y más completa, $13.0 \%$.

Respecto a la percepción de los alumnos sobre la importancia que tiene asistir a la biblioteca física y el uso de la biblioteca digital en su formación profesional, se obtuvo: (1) En total desacuerdo con esta aseveración, $2.2 \%$; (2) En desacuerdo con esta aseveración, $9.1 \%$; (3) Ni de acuerdo ni en desacuerdo con esta aseveración, 21.5 \%; (4) De acuerdo con esta aseveración, $39.7 \%$; (5) Totalmente de acuerdo con esta aseveración, $27.5 \%$.

Las medias de las variables, como se observa en la Tabla 2, resultaron superiores a 3, que es la media de los datos de la escala Likert 1 a 5 .

Tabla 2. Media y desviación estándar

\begin{tabular}{|l|c|c|c|c|c|c|c|c|c|c|}
\hline & $Y$ & $X 1$ & $X 2$ & $X 3$ & $X 4$ & $X 5$ & $X 6$ & $X 7$ & $X 8$ & $X 9$ \\
\hline Media & 3.81 & 3.53 & 3.89 & 3.44 & 3.65 & 3.28 & 3.61 & 3.61 & 3.08 & 3.68 \\
\hline $\begin{array}{l}\text { Des. } \\
\text { Tip. }\end{array}$ & 1.010 & .763 & .936 & 1.062 & .856 & .801 & .780 & .959 & 1.056 & 1.042 \\
\hline
\end{tabular}

Nota: La media que corresponde a la escala de Likert con valores de 1 al 5 es 3.

Fuente: Análisis de resultados con SPSS v. 18. Elaboración propia

El análisis de regresión lineal múltiple arrojó un coeficiente de correlación $\left(\mathrm{R}^{2}\right)$ de $70.2 \%$, es decir, las variables X1, X4, X8, X9 y X3 explican el $70.2 \%$ de la variable dependiente (uso de la biblioteca), como se puede apreciar en la Tabla3.

Tabla 3. Resumen del modelo

\begin{tabular}{|c|c|c|}
\hline R cuadrado & Error típ. de la estimación & Durbin-Watson \\
\hline .702 & .48414 & 1.869 \\
\hline
\end{tabular}

Nota: Variables predictoras: (Constante), X1, X4, X8, X9, X3.

Fuente: Análisis de resultados con SPSS v. 18. Elaboración propia.

En esta misma tabla aparece el estadístico Durbin-Watson (1.869), el cual indica que las observaciones de esta muestra no están auto-correlacionadas, dado que los valores permitidos se encuentran entre 1.5 y 2.5. El resultado de .48414 en el error típico de la estimación refiere que la dispersión de los datos (observaciones) se encuentra cerca de la recta de regresión, o bien, cerca de 0 , lo que implica que el modelo contiene una predicción aceptable. 
La Tabla 4 describe el valor del FIV (factor de inflación de la varianza), el cual se identificó inferior a 10, lo cual indica que no presenta multicolinealidad o correlación entre las variables independientes en el modelo de regresión. También se identifican los coeficientes no estandarizados beta (B); con ellos se puede determinar que la variable $X 1$ tiene un impacto de $.533, X 4$ tiene un impacto de $.411, X 8$ tiene un impacto de $.128, X 9$ tiene un impacto de .109 y X3 tiene un impacto negativo de -.065 en la variable dependiente (Y) Uso de la biblioteca. También se encuentra la significancia del modelo, la cual resultó inferior a .05 .

Tabla 4. Coeficientes del modelo de regresión

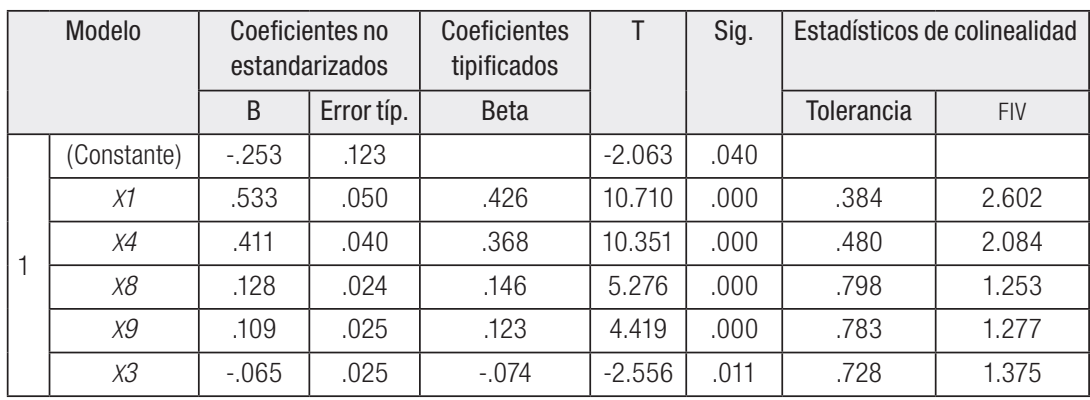

Fuente: Análisis de resultados con SPSS v. 18. Elaboración propia

La Figura 4 describe los resultados obtenidos del análisis de regresión múltiple. En ella se muestran las cinco de las nueve variables que resultaron significativas en el modelo. Dos de ellas son endógenas: (X1) Información disponible en biblioteca y (X3) Competencia del bibliotecario. Tres son exógenas; una de ellas corresponde a factores académicos: (X4) Programa de estudio, y dos a factores culturales: (X8) Hábitos de lectura y (X9) Conciencia del valor de la información.

De igual forma se puede apreciar en esta figura que las variables independientes (X2) Espacio físico disponible en biblioteca, (X5) Influencia del profesor, (X6) Habilidades informativas y (X7) Uso de Internet para actividades académicas no resultaron significativas en este modelo (muestra general).

Los datos anteriores nos permiten aceptar la hipótesis de investigación y, en los términos de este estudio, concluir que los factores que motivan a los estudiantes de las instituciones de educación superior del área metropolitana de Monterrey a utilizar la biblioteca universitaria son endógenos: Información disponible en biblioteca (X1) y Competencia del bibliotecario (X3), y exógenos: en la categoría de académicos, Programa de estudios (X4), y en la categoría de culturales, Hábitos de estudio (X8) y Conciencia del valor de la información (X9). 


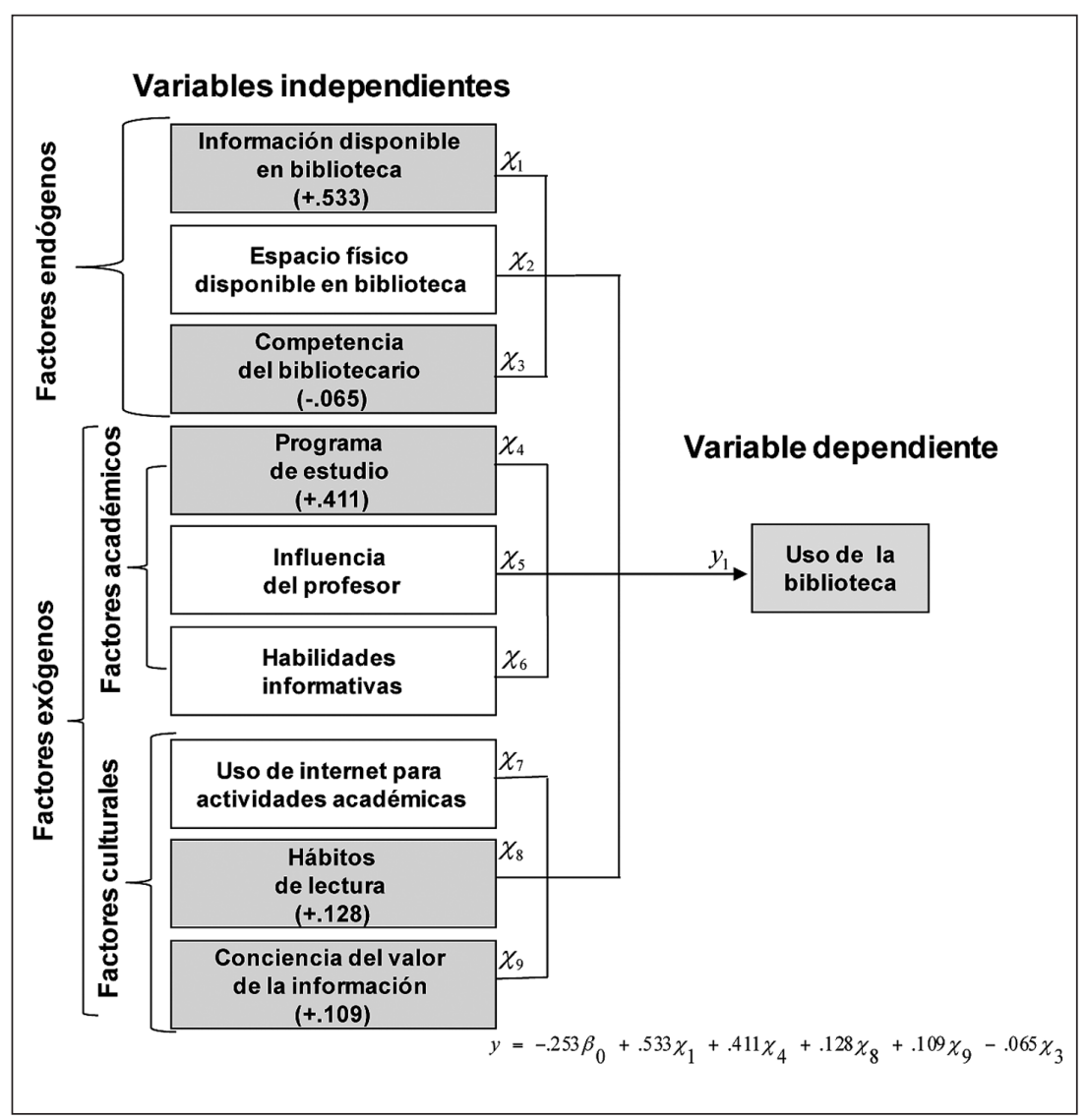

Figura 4. Modelo gráfico del análisis de regresión. Fuente: Elaboración propia

Además del análisis anterior -aplicado a la muestra general con datos de las 3 IES-, se analizaron en forma individual seis muestras, de las cuales tres son referentes a cada IES (IES 1, IES 2, IES 3) y tres a áreas del conocimiento: Ciencias de la salud, Ciencias sociales y humanidades, y Ciencias exactas.

La Tabla 5 contiene los resultados obtenidos en el análisis de regresión lineal múltiple aplicado a las siete muestras. En ella se puede identificar que el $\mathrm{R}^{2}$ más alto se obtuvo en la IES 3, a través de seis variables que resultaron significativas y que explican el 90.2 \% del uso de la biblioteca; y el más bajo se obtuvo en la IES 1 y en la muestra del área del conocimiento de Ciencias exactas, con un coeficiente de correlación que explica el $67.8 \%$ del uso de la biblioteca. 
Tabla 5. Concentrado de resultados del análisis de regresión múltiple en siete muestras

\begin{tabular}{|c|c|c|c|c|c|}
\hline Muestra & Cuestionarios & $\begin{array}{l}\text { Total } \\
\text { variables } \\
\text { Sig. }\end{array}$ & Variables Predictoras & $\mathrm{R}$ & R cuad. \\
\hline General & 490 & 5 & $\begin{array}{l}\text { X1 (ID) Información disponible en biblioteca } \\
\text { X4 (PE) Programa de estudio } \\
\text { X8(HL) Hábitos de lectura } \\
\text { X9(VI) Conciencia del valor de la información } \\
\text { X3 (CO) Competencia del bibliotecario }\end{array}$ & .838 & .702 \\
\hline IES 1 & 260 & 4 & $\begin{array}{l}\text { X1 (ID) Información disponible en biblioteca } \\
\text { X4 (PE) Programa de estudio } \\
\text { X9(VI) Conciencia del valor de la Información } \\
\text { X8 (HL) Hábitos de lectura }\end{array}$ & .823 & .678 \\
\hline IES 2 & 144 & 5 & $\begin{array}{l}\text { X1 (ID) Información disponible en biblioteca } \\
\text { X4 (PE) Programa de estudio } \\
\text { X8 (HL) Hábitos de lectura } \\
\text { X6 (HI) Habilidades informativas } \\
\text { X2 (EF) Espacio físico disponible en } \\
\text { biblioteca }\end{array}$ & .856 & .732 \\
\hline IES 3 & 86 & 6 & $\begin{array}{l}\text { X1 (ID) Información disponible en biblioteca } \\
\text { X7 (IA) Uso de Internet para actividades } \\
\text { académicas } \\
\text { X5 (IP) Influencia del profesor } \\
\text { X3 (CO) Competencia del bibliotecario } \\
\text { X6 (HI) Habilidades informativas } \\
\text { X4 (PE) Programa de estudio }\end{array}$ & .950 & .902 \\
\hline $\begin{array}{l}\text { Ciencias } \\
\text { de la salud }\end{array}$ & 123 & 4 & $\begin{array}{l}\text { X4 (PE) Programa de estudio } \\
\text { X8 }(\mathrm{HL}) \text { Hábitos de lectura } \\
\text { X9(VI) Conciencia del valor de la información } \\
\text { X7 (IA) Uso de Internet para actividades } \\
\text { académicas }\end{array}$ & .864 & .746 \\
\hline $\begin{array}{l}\text { Ciencias } \\
\text { sociales }\end{array}$ & 205 & 3 & $\begin{array}{l}\text { X1 (ID) Información disponible en biblioteca } \\
\text { X4 (PE) Programa de estudio } \\
\text { X8(HL) Hábitos de lectura }\end{array}$ & .842 & .709 \\
\hline $\begin{array}{l}\text { Ciencias } \\
\text { exactas }\end{array}$ & 164 & 5 & $\begin{array}{l}\text { X1 (ID) Información disponible en biblioteca } \\
\text { X6 (HI) Habilidades informativas } \\
\text { X4 (PE) Programa de estudio } \\
\text { X8(HL) Hábitos de lectura } \\
\text { X3 (CO) Competencia del bibliotecario }\end{array}$ & .823 & .678 \\
\hline
\end{tabular}

Fuente: Análisis de resultados con SPSS v. 18. Elaboración propia

Las variables independientes que resultaron significativas en las siete muestras analizadas en el estudio se presentan en la Tabla 6, donde se puede apreciar que la variable (X4) Programa de estudio aparece significativa en todas las muestras, mientras que (X1) Información disponible en biblioteca y (X8) Hábitos de lectura aparecen significativas en seis de las muestras. 
Por otra parte, las variables que sólo resultaron significativas en una sola muestra son (X2) Espacio físico disponible en biblioteca y (X5) Influencia del profesor. Se aprecia también que todas las variables propuestas resultaron por lo menos significativas en una de las muestras.

Tabla 6. Relación de variables independientes que resultaron significativas

\begin{tabular}{|l|c|c|c|c|c|c|c|c|}
\hline \multirow{2}{*}{ Variables independientes } & \multicolumn{7}{|c|}{ Muestra } \\
\cline { 2 - 9 } & General & IES 1 & IES 2 & IES 3 & $\begin{array}{c}\text { Ciencias } \\
\text { salud }\end{array}$ & $\begin{array}{c}\text { Ciencias } \\
\text { sociales }\end{array}$ & $\begin{array}{c}\text { Ciencias } \\
\text { exactas }\end{array}$ & Total \\
\hline $\begin{array}{l}\text { X1 (ID) Información } \\
\text { disponible en biblioteca }\end{array}$ & $X$ & $X$ & $X$ & $X$ & & $X$ & $X$ & 6 \\
\hline $\begin{array}{l}\text { X2 (EF) Espacio físico } \\
\text { disponible en biblioteca }\end{array}$ & & & $X$ & & & & & 1 \\
\hline $\begin{array}{l}\text { X3 (C0) Competencia del } \\
\text { bibliotecario }\end{array}$ & $X$ & & & $X$ & & & $X$ & 3 \\
\hline X4 (PE) Programa de estudio & $X$ & $X$ & $X$ & $X$ & $X$ & $X$ & $X$ & 7 \\
\hline $\begin{array}{l}\text { X5 (IP) Influencia del } \\
\text { profesor }\end{array}$ & & & & $X$ & & & & 1 \\
\hline $\begin{array}{l}\text { X6 (HI) Habilidades } \\
\text { informativas }\end{array}$ & & & $X$ & $X$ & & & $X$ & 3 \\
\hline $\begin{array}{l}\text { X7(IA) Uso de Internet para } \\
\text { actividades académicas }\end{array}$ & & & & $X$ & $X$ & & & 2 \\
\hline X8 (HL) Hábitos de lectura & $X$ & $X$ & $X$ & & $X$ & $X$ & $X$ & 6 \\
\hline $\begin{array}{l}\text { X9(VI) Conciencia del valor } \\
\text { de la información }\end{array}$ & $X$ & $X$ & & & $X$ & & & 3 \\
\hline \multicolumn{1}{|c|}{ Total } & 5 & 4 & 5 & 6 & 4 & 3 & 5 & \\
\hline
\end{tabular}

Fuente: Elaboración propia

\section{Conclusiones}

Los hallazgos del análisis descriptivo evidencian que en la percepción de los alumnos la biblioteca física tiene mayor importancia en su formación que la biblioteca digital; los histogramas muestran incluso una relación inversa al realizar una simple comparación visual, lo que indica que al menos para estos alumnos la biblioteca digital no es utilizada apropiadamente. Probablemente la biblioteca digital en estos casos no está incluida en los programas de estudio ni forma parte de las actividades académicas.

Como se describió anteriormente, el $67.2 \%$ de los alumnos consideraron importante a la biblioteca universitaria en su preparación profesional y necesaria para cumplir con las actividades académicas, de lo cual resulta el uso que hacen de ella. Por otra parte, se identificaron porcentajes considerables de alumnos que declararon no estar de acuerdo ni en desacuerdo con las aseveraciones, 
es decir, alumnos que no están convencidos de que la biblioteca tenga un impacto en sus actividades y en su formación académica. También es claro que las frecuencias en las declaraciones relativas a "Estoy en total desacuerdo con esta aseveración" nos permiten considerar que existen alumnos que definitivamente no consideran importante el uso de la biblioteca y por tal razón no hacen uso de ella; es decir, se trata de alumnos que no son usuarios de los servicios bibliotecarios y que al menos no son influenciados por las variables independientes consideradas en este estudio.

Como ya se mencionó, los resultados de la muestra general permiten aceptar la hipótesis de investigación y concluir que los alumnos encuestados perciben la importancia que la biblioteca universitaria, física y virtual $(Y)$ tiene en su formación profesional. El modelo de regresión lo explica en $70 \%$, y también señala que esta percepción se debe a la Información disponible en biblioteca (X1), el Programa de estudios (X4), los Hábitos de lectura (X8) y la Conciencia del valor de la información (X9). El modelo también explica que la variable Competencia del bibliotecario (X3) es crítica, ya que en el modelo los encuestados perciben una actitud desfavorable (con valor negativo) como se muestra en la Figura 4, influenciados probablemente por un servicio percibido como deficiente (es decir, deficiente en la confianza, la respuesta, la ayuda, la orientación y el trato que el bibliotecario le brinda al usuario).

En cuanto a los resultados obtenidos de las muestras las tres IES coinciden con la apreciación de Gómez (1996), quien señala que cada biblioteca universitaria constituye una realidad única, que es el resultado de múltiples factores como la cultura organizativa, el enfoque a la docencia, los recursos económicos aportados, entre otros; lo que incluso hace difícil utilizar normas o estándares para regularlas, debido a que estos estándares pueden estar hechos para realidades y entornos diferentes. Por ello, podemos entender y hasta esperar en este estudio que en cada IES resulten significativas diferentes variables.

Un ejemplo que podemos destacar es el caso de la variable independiente (X5) Influencia del profesor. Esta variable es significativa sólo en la muestra de la IES 3. La razón que explica tal resultado es que esa biblioteca tiene una práctica que no se sigue en las otras dos IES, la cual consiste en informar a los profesores y a las autoridades académicas sobre la medida en que los profesores -agrupados en departamentos académicos-provocan el uso de la biblioteca. Es decir, la biblioteca informa concretamente qué academias hacen a sus alumnos asistir a ella y cuáles no lo hacen. Esta práctica es avalada por la institución, por considerar que la asistencia a la biblioteca es una actividad básica y necesaria para los alumnos y para los objetivos institucionales. También, dicho resultado es una evidencia de buena práctica bibliotecaria, 
porque el hecho de que la variable (X5) Influencia del profesor resulte significativa es producto del impulso que la biblioteca logra con esta práctica; es decir, detrás del resultado de la variable está la acción de los bibliotecarios que lograron influir en los profesores para que colaboren con el cumplimiento de los objetivos institucionales. Por otra parte, el resultado deficiente de esta variable en la muestra general puede estar asociado al modelo educativo basado en el profesor y en un libro de texto, donde el alumno no necesita asistir a la biblioteca a investigar, sino "machetear" su libro (de texto) para aprobar un examen y con ello el curso.

Es importante destacar en este estudio el consistente comportamiento de las siguientes tres variables independientes. La primera, (X4) Programa de estudio, aparece significativa en las siete muestras -salvo en el caso de la IES 3, donde aparece en segundo lugar-, lo que nos indica que el programa de estudio es un fuerte impulsor del uso de la biblioteca; por ello, convendría investigar en qué medida los programas de estudio contemplan el uso de la biblioteca, y si éstas consideran en sus adquisiciones los documentos que aparecen en dichos programas, porque este resultado parecería ser producto de dicha práctica; valdría la pena verificarlo, como recomendación para futuros estudios.

La segunda variable, (X1) Información disponible en biblioteca -que resultó significativa en seis muestras, salvo en Ciencias de la salud-, aparece en primer lugar en los modelos, por lo que resulta ser la variable independiente que principalmente explica la variable $(Y)$ Uso de la biblioteca. Este resultado es también lógico dado que los usuarios de la biblioteca asisten principalmente para dos cosas: 1) para buscar información o 2) para buscar un espacio donde consultar sus propios documentos.

Un resultado también significativo es el referente a la variable (X6) Habilidades informativas, la cual resultó significativa sólo en las IES privadas (2 y 3), por lo que se concluye que en ellas se ha logrado una mayor capacitación o sensibilidad respecto al manejo y el adecuado uso de la información. Es asimismo notable que las variables (X2) Espacio físico disponible en biblioteca y (X5) Influencia del profesor no aparecen significativas en ninguna de las muestras por área del conocimiento, lo que implica la necesidad de realizar un análisis más profundo de estos resultados individuales.

\section{RECOMENDACIONES}

Una primera recomendación que surge de la variable (X6) Habilidades informativas estaría dirigida a la creación de un programa institucional relacionado 
con el desarrollo de habilidades informativas (DHI), y que este programa se logre incorporar al plan de estudios, tal como lo implementa con éxito la Universidad Autónoma de Ciudad Juárez, con los beneficios que la alfabetización informativa brinda para el óptimo desempeño de todo profesional en estos tiempos de alta tecnología y de grandes volúmenes de información. Es importante señalar que un programa de DHI no es suficiente para aspirar al logro de una cultura de la información a nivel institucional, dado que este tipo de programas tiene como alcance sólo a los alumnos que se inscriben en dichos cursos. Para aspirar a una meta mayor -es decir, que la cultura de la información abarque a la totalidad de una comunidad universitaria, conformada por alumnos, profesores y administrativos-, se requieren programas de acción relacionados con el logro de objetivos de alcance institucional. Como ejemplo citaremos a la IES 3, que recientemente logró definir las competencias básicas informacionales que deben poseer sus profesores, las cuales son instituidas como requerimientos para la práctica docente y forman parte también de indicadores y objetivos institucionales.

Otra futura línea de investigación sería analizar si las variables propuestas en este estudio son consideradas por la academia como competencias básicas para el perfil de un alumno de nivel de educación superior y para su perfil de egreso. Si tal fuera la situación, como consideramos en lo personal, es de suma importancia conocer por qué los alumnos que respondieron estar en desacuerdo con las aseveraciones del instrumento de acopio de información no son influidos por estas variables y cómo es que ellos solucionan sus necesidades de información, con qué documentos y de qué calidad, ya que ello necesariamente tiene impacto en la formación profesional que reciben. Adicionalmente, valdría la pena conocer si existen mejores estrategias para adquirir información, para las actividades académicas y de investigación en el nivel superior, diferentes a las que se conocen y utilizan en la biblioteca universitaria física y digital. Asimismo, consideramos pertinente conocer las causas por las cuales la variable (X5) Influencia del profesor no resultó significativa en el estudio, considerando que el profesor es parte fundamental del proceso enseñanza-aprendizaje.

Otra futura línea de investigación es la relacionada con la variable (X2) Espacio físico disponible en biblioteca, que resultó significativa sólo en la IES 2. Al respecto tenemos dos cuestionamientos; el primero de ellos es referente a conocer si influye en este resultado que los alumnos sean foráneos, y el segundo, si la adquisición de información a través de las TIC está influyendo en el uso del espacio físico de las bibliotecas universitarias. También es importante investigar si existen diferencias entre los factores que motivan el uso de la biblioteca en las IES públicas y privadas. Asimismo, un estudio de suma 
importancia es el relacionado con identificar si existen diferencias en los factores que motivan el uso de la biblioteca entre los alumnos catalogados como usuarios y los catalogados como no usuarios.

Los resultados de este estudio pretenden reflexionar sobre el uso y servicios de la biblioteca, analizar y evaluar su impacto en la comunidad de usuarios y contribuir como modelo que permita acopiar información para la toma de decisiones y la planificación de los servicios. En última instancia, más allá del valor teórico o explicativo de este estudio y de la aplicación práctica que el mismo pueda tener, consideremos esta aportación como una propuesta e invitación para continuar aplicando el rigor científico a la esfera de la bibliotecología y las ciencias de la información.

Nota

El presente artículo surge de la disertación Factores que motivan el uso de la biblioteca: Estudio de caso en tres Instituciones de Educación Superior del área metropolitana de Monterrey, Nuevo León, presentada por José Segoviano Hernández el 6 de julio de 2012, para obtener el grado de Doctor en Filosofía con especialidad en Administración, de la Facultad de Contaduría Pública y Administración en el Centro de Desarrollo Empresarial y Posgrado.

\section{BiBLIOGRAFÍA}

Arias Coello, A. y Simón Martín, J. (2008), "Estudio de los hábitos de uso de los estudiantes en la biblioteca de la Universidad Complutense de Madrid”, en Revista Española de Documentación Científca, 31 (3), pp. 413-431.

Booth, A. (2008), "Using evidence in practice: In search of the mythical 'typical library user' ", en Health Information and Libraries Journal, 25 (3), pp. 233-236.

Calva González, J. J. (2004), “La investigación sobre las necesidades de información en comunidades de usuarios", en Investigación bibliotecológica: archivonomía, bibliotecología e información, 18 (37), pp. 23-55.

Calvert, P. J. (2001), "International Variations in Measuring Customer Expectations”, en Library Trends, 49 (4), pp. 732-57.

Cortés Vera, J. J. (2007), “El desarrollo de competencias informativas en estudiantes universitarios a través de un curso con valor en créditos”, en Biblios: Revista de Bibliotecología y Ciencias de la Información, 29, pp. 1-12. 
Delgado López-Cózar, E. (2002), La investigación en biblioteconomía y documentación, Gijón, Asturias: Ediciones Trea.

Fuentes, J. J. (1999), Evaluación de bibliotecas y centros de documentación e información, Gijón, Asturias: Ediciones Trea.

Gómez Hernández, J. A. (1996), La función de la biblioteca en la Educación Superior: estudio aplicado a la Biblioteca Universitaria de Murcia, tesis doctoral, Universidad de Murcia, disponible en TDR: http://www.tesisenred.net y en E-LIS: http://eprints.rclis. org/archive/00008002/01/gomezhernandez.pdf

González Teruel, A. (2005), Los estudios de necesidades y usos de la información: fundamentos y perspectivas actuales, Somonte-Cenero, Gijón: Ediciones Trea.

Gutiérrez Valencia, A. (2009), "El estudio de las prácticas y las representaciones sociales de la lectura: génesis y el estado del arte”, en Anales de Documentación, 12, pp. 53-67.

Jones, S. y Madden, M. A. (2002), “The Internet goes to college: How students are living in the future with today's technology", en Pew Internet \& American Life Project, disponible en: http://www.pew internet.org/reports/pdfs/PIP\%5FCollege\%5FReport.pdf (Fecha de consulta: 11 de diciembre de 2012).

Lau, J. y Cortés, J. (1995), “La agenda rezagada: la formación de usuarios de sistemas de información", presentado en el VII Coloquio de Automatización de Bibliotecas, Colima, México, disponible en: http://bivir.uacj.mx/dhi/PublicacionesUACJ/Docs/Ponencias/ PDF/poncol95.pdf (Fecha de consulta: 18 de diciembre de 2013).

Lee, S. (2007), Academic library service consumer (user) motivation study based on expectancy theory, tesis doctoral, Florida State University, disponible en: http://etd.lib.fsu.edu/theses/available/etd11102007-214504

López Yepes, J. (2004), Diccionario enciclopédico de ciencias de la documentación, Madrid: Editorial Síntesis.

Lovato-Gassman, B. (2007), User satisfaction and library use, tesis doctoral, New Mexico State University.

Martell, C. (2008), "The Absent User: Physical Use of Academic Library Collections and Services Continues to Decline 1995-2006", en The Journal of Academic Librarianship, 34 (5), pp. 400-407.

Mason, M. K. (2010), "Myths Associated With Undergraduate Use of Academic Libraries", disponible en: http://www.moyak.com/pa pers/academic-library-anxiety.html (Fecha de consulta: 4 de enero de 2013).

Oakleaf, M. J. (2010), "The value of academic libraries: A comprehensive research review and report", en Association of College and Research Libraries, Chicago, disponible en: http://www.acrl.ala.org/ value/ (Fecha de consulta: 3 de enero de 2013).

Palma Peña, J. M. (2009), "La alfabetización informativa tecnológica: estrategia fundamental en las bibliotecas del Siglo XXI", en Revista Interamericana de Bibliotecología, Medellín, 32 (01), pp. 155-172. 
Ramírez Leyva, E. M. (1987), "Factores que inciden en la frecuencia de uso de la biblioteca pública”, en Investigación bibliotecológica: archivonomía, bibliotecología e información, 1 (2), pp. 41-50.

Red de Bibliotecas Universitarias (2007), II Plan estratégico 2007-2010. Linea estratégica 3: REBIUN y calidad, disponible en: www.rebiun. org/doc/informe_libqual.pdf (Fecha de consulta: 12 de diciembre de 2012).

Simmonds, P. L. y Andaleeb, S. S. (2001), "Usage of Academic Libraries: The Role of Service Quality, Resources and User Characteristics", en Library Trends, 49 (4), pp. 626-34.

Teoh, Z. M. y Tan, A. K. G. (2011), "Determinants of library use amongst university students", en Malaysian Journal of Library $\mathcal{E}$ Information Science, 16 (2), pp. 21-31.

Toner, L. J. (2008), "Non-use of Library Services by Students in a UK Academic Library", en Evidence Based Library and Information Practice, 3 (2), pp. 18-29.

Whitmire, E. (2001), “The relationship between undergraduates' background characteristics and college experiences and their academic library use", en College E Research Libraries, 62 (6), pp. 528-540. 